Supporting Information for

Obtaining and application the nanohybrid palygorskite-rifampicin in the pH-responsive release of tuberculostatic drug

Elmar Damasceno Junior ${ }^{1 *}$, Janiele Mayara Ferreira de Almeida ${ }^{1}$, Isabel do Nascimento Silva ${ }^{1}$, Mikaely Lizandra Moreira de Assis ${ }^{1}$, Lamara Maciel dos Santos ${ }^{1}$, Elizete Faustino Dias ${ }^{1}$, Francisco Emanuel da Silva ${ }^{1}$, Nedja Suely Fernandes ${ }^{1}$, Djalma Ribeiro da Silva ${ }^{1}$.

*Corresponding author. E-mail: elmarjunior12@gmail.com

${ }^{1}$ Universidade Federal do Rio Grande do Norte, Instituto de Química, Campus

Universitário Lagoa Nova, Natal-RN, Brasil.

Number of pages: 7

Number of figures: 2

Number of tables: 6 


\section{Validation parameters}

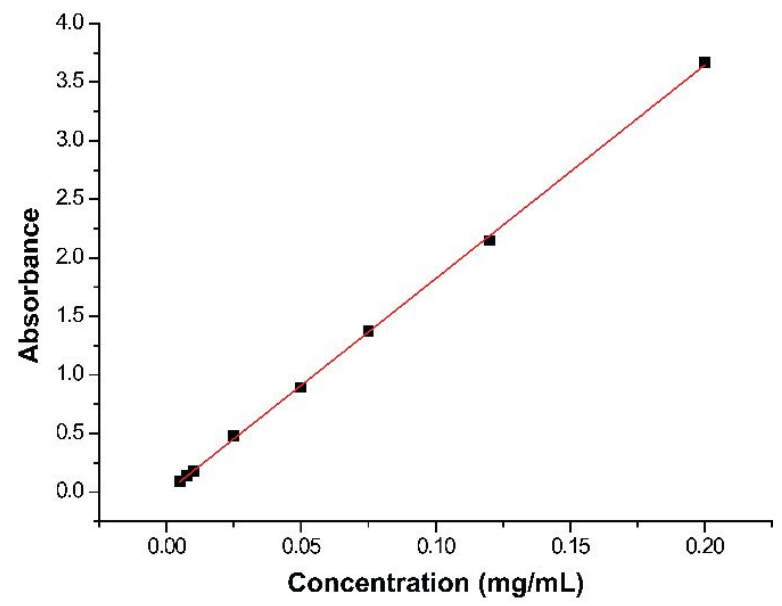

Figure S1. Average calibration curve for RIF.

Table S1. Values of linear coefficient, angular coefficient and linear correlation coefficient $\left(\mathrm{r}^{2}\right)$.

\begin{tabular}{cccc}
\hline Calibration curve & Linear coefficient & $\begin{array}{c}\text { Angular } \\
\text { coefficient }\end{array}$ & $\mathbf{r}^{\mathbf{2}}$ \\
\hline 1 & 0.0078 & 18.2430 & 0.9994 \\
\hline 2 & 0.0002 & 18.2270 & 0.9997 \\
\hline 3 & 0.0019 & 18.2340 & 0.9995 \\
\hline
\end{tabular}

Table S2. Values obtained from the calibration curves for the calculation of the detection limit (LD) and the quantification limit (LQ).

\begin{tabular}{cccc}
\hline IC & $\boldsymbol{\sigma}$ & Detection limit (LD) & $\begin{array}{c}\text { Quantification limit } \\
\text { (LQ) }\end{array}$ \\
\hline 18,234 & 0.0039887 & $0.000722 \mathrm{mg} / \mathrm{mL}$ & $0.002187 \mathrm{mg} / \mathrm{mL}$ \\
\hline
\end{tabular}




\section{Adsorption Kinetics}

Table S3. Kinetic adsorption models

\begin{tabular}{ccc}
\hline Kinetic model & Model equation & Linearized form \\
\hline Pseudo-first order & $q_{t}=q_{e}\left(1-e^{\left(-k_{1} t\right)}\right)$ & $\ln \left(q_{e}-q_{t}\right)=\ln q_{e}-k_{1} t$ \\
\hline Pseudo-second order & $q_{t}=\frac{k_{2} q_{e}^{2} t}{1+k_{2} q_{e}^{2} t}$ & $\frac{t}{q_{t}}=\frac{1}{k_{2} q_{e}^{2}}+\frac{t}{q_{e}}$ \\
\hline Intraparticle diffusion & $q_{t}=k_{d i f} \sqrt{t}+C_{i}$ \\
\hline Elovich & $\left(\frac{d q_{t}}{d t}\right)=\alpha \exp \left(-\beta q_{t}\right)$ & $q_{t}=\left(\frac{1}{\beta}\right) \ln (\alpha \beta)+\left(\frac{1}{\beta}\right) \ln t$
\end{tabular}

$\overline{q_{e}, q_{t}-\text { amount of drug adsorbed in equilibrium at any time }(\mathrm{mg} / \mathrm{g}) ; k_{l}-\text { pseudo-first order }}$ constant $\left(\mathrm{min}^{-1}\right) ; k_{2}-$ constant of the pseudo-second order (g/mg.min); $k_{d i f}-$ intraparticle diffusion constant (mg/g. $\left.\min ^{1,5}\right) ; C_{\mathrm{i}}-$ boundary layer thickness $(\mathrm{mg} / \mathrm{g}) ; t-$ tine; $\alpha$ and $\beta$ are constant throughout the experiment.

\section{Adsorption isotherm}

Table S4. Adsorption isotherm models

\begin{tabular}{ccc}
\hline Isotherm & Model equation & Linearized form \\
\hline Langmuir & $q_{e}=\frac{q_{m} K_{L} C_{e}}{1+K_{L} C_{e}}$ & $\frac{C_{e}}{q_{e}}=\frac{1}{q_{m} K_{L}}+\frac{1}{q_{m}} C_{e}$ \\
\hline Freundlich & $q_{e}=K_{F} C_{e}^{\frac{1}{n}}$ & $\log q_{e}=\log K_{F}+\frac{1}{n} \log C_{e}$ \\
\hline Temkin & $q_{e}=\frac{R T}{b_{T}} \ln \left(A_{T} C_{e}\right)$ \\
\hline $\begin{array}{l}C_{e}-\text { equilibrium drug concentration (mg/L); } q_{e}-\text { equilibrium adsorption capacity }(\mathrm{mg} / \mathrm{g}) ; \\
K_{L}-\text { Langmuir constant (L/mg); } q_{m}-\text { maximum adsorption capacity }(\mathrm{mg} / \mathrm{g}) ; n-\mathrm{empirical} \\
\text { parameter for adsorption intensity; } K_{F}-\text { Freundlich constant }(\mathrm{mg} / \mathrm{g})(\mathrm{mg} / \mathrm{L})(-1 / \mathrm{n}) ; A_{T}-\mathrm{bond}\end{array}$
\end{tabular}


equilibrium constant $(\mathrm{L} / \mathrm{mg}) ; b_{T}$ - adsorption heat $(\mathrm{J} / \mathrm{mol}) ; R-$ universal gas constant (J/mol.K); $T$ - temperature $(\mathrm{K})$.

\section{Kinetic release models}

Table S5. Mathematical models of release kinetics used in the evaluation of the INH release profile from PAL.

\begin{tabular}{ccc}
\hline Model & Equation* $^{*}$ & Graphics plotted \\
\hline Zero order & $\mathrm{Q}_{\mathrm{t}}=\mathrm{Q}_{0}+\mathrm{K}_{0} \mathrm{t}$ & $\mathrm{Q}_{\mathrm{t}}$ verus $\mathrm{t}$ \\
\hline First order & $\ln \mathrm{Q}_{\mathrm{t}}=\ln \mathrm{Q}_{0}+\mathrm{k}_{1} \mathrm{t}$ & $\log \mathrm{Q}_{\mathrm{t}}$ versus $\mathrm{t}$ \\
\hline Higuchi & $\mathrm{Q}_{\mathrm{t}}=\mathrm{K}_{\mathrm{H}} \cdot \mathrm{t}^{1 / 2}$ & $\mathrm{Q}_{\mathrm{t}}$ versus $\mathrm{t}^{1 / 2}$
\end{tabular}

${ }^{*} \mathrm{Q}_{\mathrm{t}}-$ amount of drug released at time $\mathrm{t} ; \mathrm{Q}_{0}-$ initial amount of drug in solution; $\mathrm{K}_{0}, \mathrm{~K}_{1}$, $\mathrm{K}_{\mathrm{H}}-$ constant characteristics of each model;

\section{Rifampicin stability study}

Table S6. Stress conditions in which each sample was maintained throughout the RIF stability study in aqueous solution.

\begin{tabular}{cccc}
\hline Sample & pH & Temperature & AA (1 mg/mL) \\
\hline 01 & 2 & $4{ }^{\circ} \mathrm{C}^{*}$ & Absent \\
\hline 02 & 6 & $4{ }^{\circ} \mathrm{C}^{*}$ & Absent \\
\hline 03 & 2 & $25{ }^{\circ} \mathrm{C}$ & Absent \\
\hline 04 & 6 & $25{ }^{\circ} \mathrm{C}$ & Absent \\
\hline 05 & 2 & $4{ }^{\circ} \mathrm{C}^{*}$ & Present \\
\hline 06 & 6 & $4{ }^{\circ} \mathrm{C}^{*}$ & Present \\
\hline 07 & 2 & $25^{\circ} \mathrm{C}$ & Present \\
\hline 08 & 6 & $25^{\circ} \mathrm{C}$ & Present
\end{tabular}

*Under refrigeration. 
Global pharmaceutical agencies, such as the American Pharmacopoeia and the WHO, claim that the main stress conditions for analyzing the stability of working analytical solutions containing medicines are $\mathrm{pH}$, temperature and the influence of light 1,2. Figure S2 shows the graphs of RIF degradation (\%) versus time in the absence (Figure 2a) and in the presence (Figure S2b) of AA.

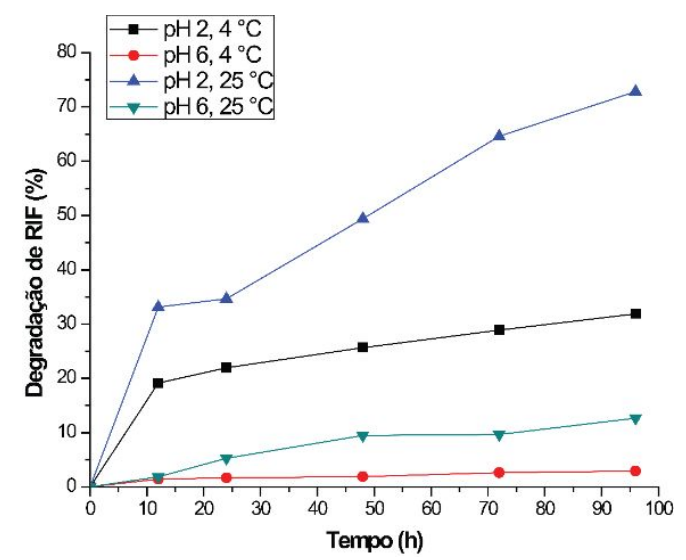

(a)

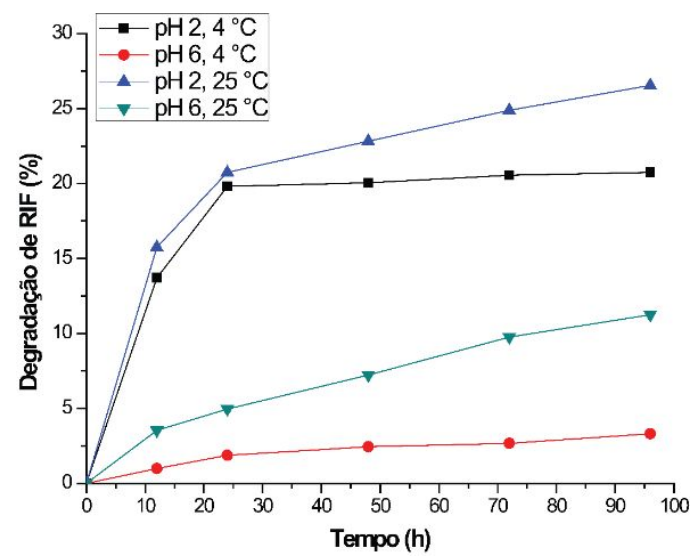

(b)

Figure S2. RIF degradation curves under different stress conditions (a) in the absence of AA and (b) in the presence of AA

As seen in Figure S2a, rifampicin showed greater stability in solution maintained at $\mathrm{pH} 6$, with a minimum degradation of approximately $2.5 \%$ at the end of the experiment. At $\mathrm{pH} 2$ values, it can be seen that the drug presents a high degradation, reaching almost its totality in 4 days of storage. According to the literature, RIF is 
degraded at low $\mathrm{pH}$ values by about $8.5 \%$ to $50 \%$. This degradation occurs due to its hydrolysis in the acidic environment, leading to the formation of 3-formyl-rifamycin (3FRSV) ${ }^{3-6}$.

The effect of the storage temperature of the solution was also evaluated. It can be noted that the RIF has greater stability at lower temperatures $\left(4^{\circ} \mathrm{C}\right)$. Therefore, solutions prepared for later use should be stored under refrigeration to avoid as much degradation as possible.

The effect of adding ascorbic acid was quite significant, as seen in Figure 10b. Ascorbic acid acts as an antioxidant and minimizes drug degradation in acidic environments 7,8 . The percentage of degraded RIF was around $25 \%$ after 4 days of observation. This result proves the beneficial effect of adding AA which, under refrigeration, manages to stabilize the drug solution for a considerable period of time. According to Rajaram, Vemuri and Natham (2014) ${ }^{7}$, the formation of free radicals in an acid medium may be the factor that influences the degradation of RIF to 3-FRSV. Thus, AA prevents the degradation of RIF through its mechanism of eliminating free radicals.

Even with degradation in acidic medium, rifampicin shows a significant increase in its solubility in $\mathrm{pH}$ values between 1-2 3,8 . Thus, in order to maximize the interaction between the drug molecules and the PAL surface in obtaining clay-drug hybrids, the RIF incorporation process was evaluated at $\mathrm{pH} 2$. Ascorbic acid at a concentration of $1 \mathrm{mg} / \mathrm{mL}$ was added to the solutions prepared and the values of degradation obtained for $24 \mathrm{~h}$ (approximately $21 \%$ ), maximum time in which the solution remains in contact with the nanocarrier particles, were considered in all calculations of the present study.

\section{References}

(1) Jamrógiewicz, M.; Pieńkowska, K. Recent Breakthroughs in the Stability Testing of Pharmaceutical Compounds. TrAC - Trends in Analytical Chemistry. 2019. https://doi.org/10.1016/j.trac.2018.12.007.

(2) Sengupta, P.; Chatterjee, B.; Tekade, R. K. Current Regulatory Requirements and Practical Approaches for Stability Analysis of Pharmaceutical Products: A Comprehensive Review. International Journal of Pharmaceutics. 2018. https://doi.org/10.1016/j.ijpharm.2018.04.007.

(3) Freire, F. D.; Câmara, M. B.; Dantas, M. G.; Aragão, C. F. S.; De Lima E Moura, 
T. F. A.; Raffin, F. N. Gastric-Resistant Isoniazid Pellets Reduced Degradation of Rifampicin in Acidic Medium. Brazilian J. Pharm. Sci. 2014.

https://doi.org/10.1590/S1984-82502014000400010.

(4) Prankerd, R. J.; Walters, J. M.; Parnes, J. H. Kinetics for Degradation of Rifampicin, an Azomethine-Containing Drug Which Exhibits Reversible Hydrolysis in Acidic Solutions. Int. J. Pharm. 1992. https://doi.org/10.1016/0378-5173(92)90355-6.

(5) Shaikh, T.; Pandey, A.; Sirajuddin; Talpur, F. N.; Kaushik, A.; Niazi, J. H. Gold Nanoparticles Based Sensor for in Vitro Analysis of Drug-Drug Interactions Using Imipramine and Isoniazid Drugs: A Proof of Concept Approach. Sensors Actuators, B Chem. 2017. https://doi.org/10.1016/j.snb.2017.06.083.

(6) Singh, S.; Mariappan, T. T.; Sharda, N.; Singh, B. Degradation of Rifampicin, Isoniazid and Pyrazinamide from Prepared Mixtures and Marketed Single and Combination Products under Acid Conditions. Pharm. Pharmacol. Commun. 2000. https://doi.org/10.1211/146080800128735575.

(7) Rajaram, S.; Vemuri, V. D.; Natham, R. Ascorbic Acid Improves Stability and Pharmacokinetics of Rifampicin in the Presence of Isoniazid. J. Pharm. Biomed. Anal. 2014. https://doi.org/10.1016/j.jpba.2014.07.027.

(8) Alves, R.; Reis, T. V. D. S.; Da Silva, L. C. C.; Storpírtis, S.; Mercuri, L. P.; Matos, J. D. R. Thermal Behavior and Decomposition Kinetics of Rifampicin Polymorphs under Isothermal and Non-Isothermal Conditions. Brazilian J. Pharm. Sci. 2010. https://doi.org/10.1590/S1984-82502010000200022. 